\title{
Corrigendum
}

\section{Corrigendum to "An Impulse-C Hardware Accelerator for Packet Classification Based on Fine/Coarse Grain Optimization"}

\author{
O. Ahmed $(\mathbb{D}$, S. Areibi $(\mathbb{D}$, R. Collier $(\mathbb{D}$, and G. Grewal $(1)$ \\ Faculty of Engineering and Computer Science, University of Guelph, Guelph, ON, Canada \\ Correspondence should be addressed to S. Areibi; sareibi@uoguelph.ca
}

Received 26 February 2018; Accepted 27 February 2018; Published 21 June 2018

Copyright (C) 2018 O. Ahmed et al. This is an open access article distributed under the Creative Commons Attribution License, which permits unrestricted use, distribution, and reproduction in any medium, provided the original work is properly cited.

In the article titled "An Impulse-C Hardware Accelerator for Packet Classification Based on Fine/Coarse Grain Optimization" [1], the authors acknowledge the minor reuse of text from their following two conference papers:

(1) M. Walton, G. Grewal, and G. Darlington. 2010. "Parallel FPGA-based implementation of scatter search". In Proceedings of the 12th annual conference on Genetic and evolutionary computation (GECCO '10). ACM, New York, NY, USA, 1075-1082. doi: https://dx.doi.org/10.1145/1830483.1830683.

(2) O. Ahmed, K. Chattha and S. Areibi, "A hardware/ software co-design architecture for packet classification," 2010 International Conference on Microelectronics, Cairo, 2010, pp. 96-99. doi: 10.1109/ICM.2010 .5696215 .

\section{References}

[1] O. Ahmed, S. Areibi, R. Collier, and G. Grewal, "An impulseC hardware accelerator for packet classification based on fine/coarse grain optimization," International Journal of Reconfigurable Computing, vol. 2013, Article ID 130765, 23 pages, 2013. 


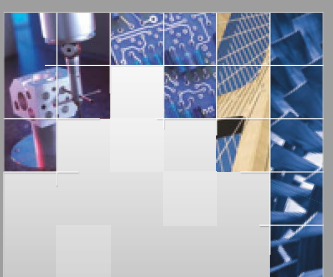

\section{Enfincering}
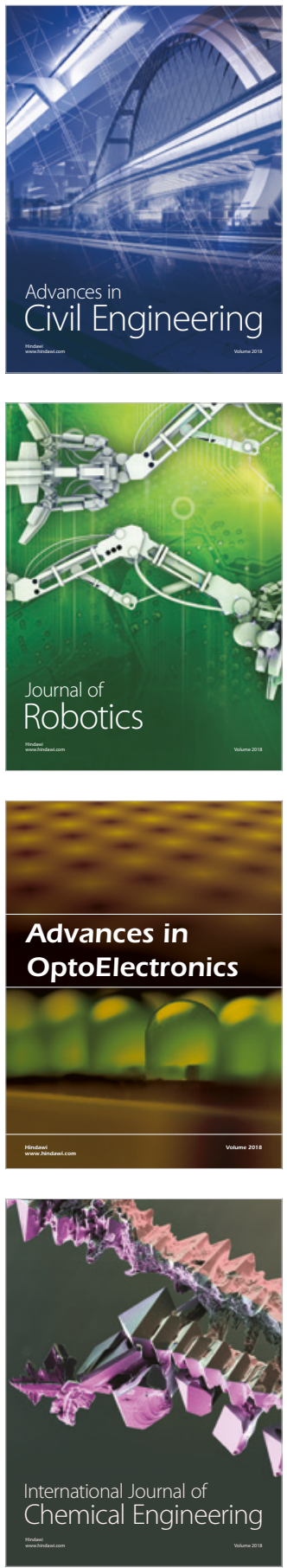

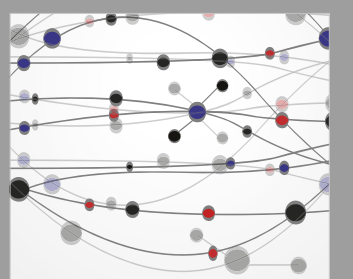

\section{Rotating \\ Machinery}

The Scientific World Journal

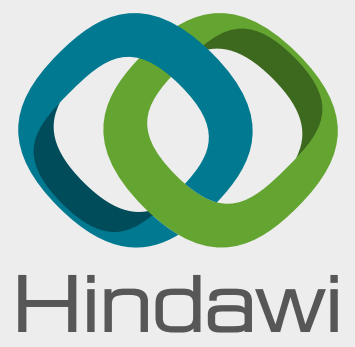

Submit your manuscripts at

www.hindawi.com
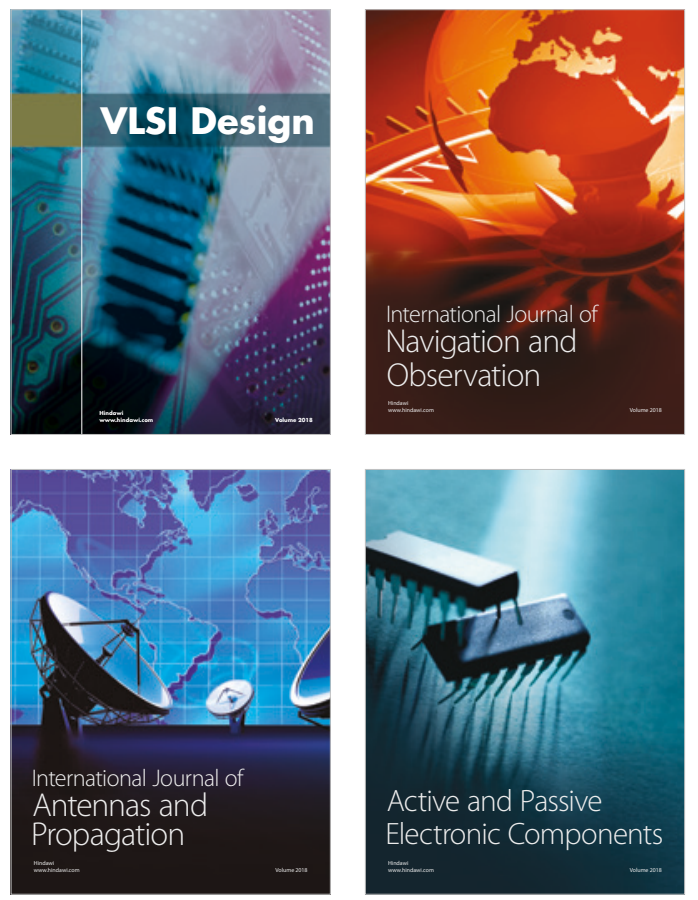
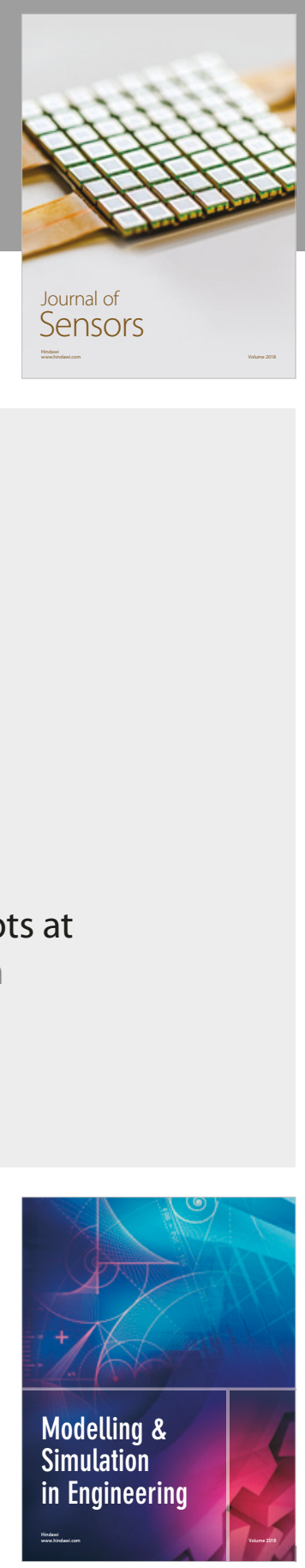

\section{Advances \\ Multimedia}
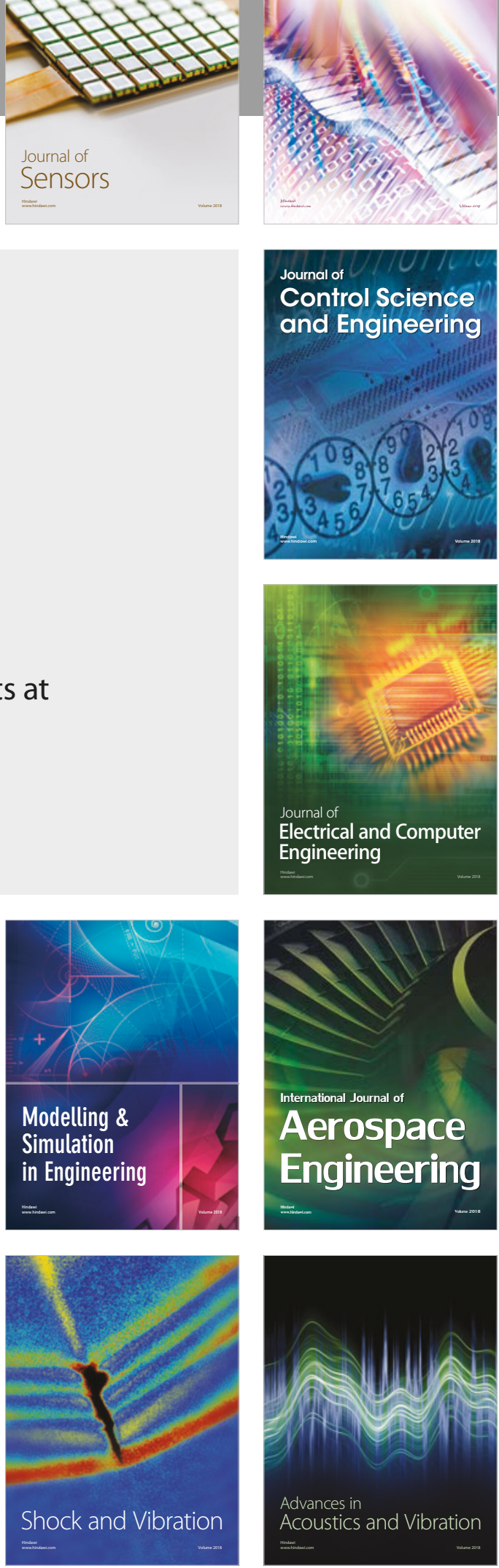